\title{
Una vocación indicial: experticia policial en los modos de investigar, informar y vigilar en la Provincia de Buenos Aires y el Territorio Nacional de Río Negro (1930-1943)
}

\author{
An indicial vocation: police expertise in the ways of investigating, informing and \\ surveilling in the Province of Buenos Aires and the National Territory of Río \\ Negro (1930-1943)
}

\author{
Pedro Berardi \\ pedroberardi@hotmail.com \\ Universidad de San Andrés / Universidad \\ Torcuato Di Tella, Argentina
}

\author{
Melisa Fernández Marrón \\ mfmarron@unrn.edu.ar \\ Universidad Nacional de Río Negro, Instituto de \\ Investigación en Políticas Públicas y Gobierno, \\ Argentina
}

Recepción: 15 Abril 2021

Aprobación: 17 Mayo 2021

Publicación: 01 Junio 2021

Cita sugerida: Berardi, P. y Fernández Marrón, M. (2021). Una vocación indicial: experticia policial en los modos de investigar, informar y vigilar en la Provincia de Buenos Aires y el Territorio Nacional de Río Negro (1930-1943). Aletheia, 11(22), e085. https://doi.org/10.24215/18533701e085
Resumen: Las secciones y divisiones dedicadas a la inteligencia y seguimiento político y social son centrales en la historia de las policías argentinas. La historiografía reciente ha destacado la complejidad de interpretar las políticas estatales de seguridad y sus transformaciones en el tiempo como producto de un proceso de larga duración. Este artículo examina las modalidades y prácticas de investigación desarrolladas por las policías del Territorio Nacional de Río Negro y de la Provincia de Buenos Aires entre 1930 y 1943. Un abordaje que radica en ponderar las especificidades institucionales propias de un período escasamente transitado para estos escenarios a partir de tres ejes: primero, recompone el proceso de burocratización interno que transitarían ambas reparticiones producto de estas tareas. Segundo, estas secciones construyeron una sólida tradición de información materializada en informes, expedientes y prontuarios. En ese sentido, se pone el foco en los agentes que se configuraron como un grupo de "expertos" en su producción como en las lógicas para la recolección de información. Por último, se incursiona en los sentidos otorgados a los actores "observados".

Palabras clave: Secciones, Policía, Investigar, Provincia de Buenos Aires, Territorio Nacional de Río Negro.

Abstract: The sections and divisions dedicated to intelligence and political and social policing are central to the history of the Argentine police. Recent historiography has highlighted the complexity of interpreting state security policies and their transformations over time as the product of a long-term process. This article examines the modalities and practices of investigation developed by the police forces of the National Territory of Río Negro and the Province of Buenos Aires between 1930 and 1943. The approach is based on pondering the institutional specificities of a period that was little explored in these scenarios from three points of view: first, it reconstructs the process of internal bureaucratisation that both departments underwent as a result of these tasks. Secondly, these sections built up a solid tradition of information materialised in reports, 
dossiers and files. In this sense, the focus is on the agents who became a group of "experts" in their production, as well as on the logics of information gathering. Finally, we look at the meanings given to the actors "observed".

Keywords: Sections, Police, Investigate, Province of Buenos Aires, National Territory of Río Negro.

\section{INTRODUCCIÓN}

A lo largo de las primeras décadas del siglo XX, en Argentina, la policía concibió la importancia de producir conocimiento detallado sobre los distintos actores sociales y políticos observados de peligrosos. Esa configuración habilitó una experticia en las modalidades de investigar y vigilar. Una serie de estudios refrendan la impresión de que los estilos de seguimiento y los procedimientos de investigación como los de inteligencia asentados en la burocracia policial pueden considerarse partes centrales para comprender los dispositivos de control, violencia y represión estatal en la larga duración (Bohoslavsky y Franco, 2020). Lo cierto es que, por fin, han comenzado a circular trabajos que se abocan a indagar los orígenes y desarrollo de la comisaría, luego devenida División de Investigación, en diferentes temporalidades y espacios (García Ferrari, 2015; López, 2021; Galeano y Albornoz, 2020; Bartolucci, 2020; Scocco, 2019; Barreneche, 2019; Águila, 2013) como los modos y las prácticas de información e inteligencia desplegados sobre determinados actores (Águila, 2018; López Cantera, 2014; Benclowicz, 2019; Albornoz y Galeano, 2017; Marengo, 2012). A todo esto, ciertas contribuciones han colocado su indagación histórica sobre los años treinta y cuarenta del siglo $\mathrm{XX}$; que demostraron el peso renovado de comprender la conformación de las oficinas y secciones destinadas a la investigación policial atendiendo a sus singularidades en el tiempo (Luciano, 2019, 2021; Barry, 2019; Kalmanowiecki, 1997; Caimari, 2012).

El accionar de la Sección Orden Social reordenada en la policía de la Provincia de Buenos Aires y creada en la institución análoga del Territorio Nacional de Río Negro durante los años treinta, es el tema central de este artículo. En el primer caso, abundan estudios que retoman dicha sección como un antecedente directo en la genealogía de la Dirección de Inteligencia de la Policía de la Provincia de Buenos Aires -DIPBA- (Funes, 2004; Flier, 2015); en el segundo, existen escasas aproximaciones a la temática (Suárez, 2013a, 2013b).

Nuestro punto de partida son aquellos mecanismos de investigación e información policial que fueron rubricando formas de observación e intervención sostenidas en el sigilo y en la asidua permanencia, que se transformaron constantes en el control de las multitudes en el transcurso de los años '20. Como referiremos más adelante, las hibridaciones producidas entre el control de movimientos gremiales y la supervisión de las agrupaciones partidarias, fueron configurando una multiplicidad de saberes y experticias acumuladas que para mediados de los '30 capitalizaría la División de Investigaciones. Si bien la condensación de prácticas de investigación y seguimiento permite trazar un hilo de largas duraciones, más allá de las cesuras cronológicas que toman al golpe de 1930 como un hito, el giro autoritario que gravitaría en el espacio bonaerense y rionegrino constituyó un marco propicio para su resignificación en el devenir de las actividades represivas que se afianzarían durante ese decenio y los años siguientes.

De esta forma, una primera parte del texto se ocupa del escenario en el que se gestaron los distintos mecanismos de vigilancia e investigación policial en el espacio bonaerense y rionegrino. Un segundo momento converge en explorar las características de las tareas de inteligencia. Para ello, se pone el foco en los agentes que se configuraron como un grupo de especialistas o expertos en su producción como en las tecnologías implementadas y en los vínculos, saberes y lógicas para la recolección de información.

Para eso, esta investigación combina el análisis de archivos de diferente naturaleza. Por un lado, se hará un intenso uso de un corpus de documentación producida por las mismas agencias estatales: órdenes del 
día, reglamentos, legislación, legajos de personal y expedientes que permiten acercarse a la organización, las normativas, las actuaciones y las formas de administrar el disciplinamiento. Se han incluido, por otro lado, diarios de sesiones de la Cámara de Diputados de la Nación y de la Legislatura bonaerense, conferencias, boletines oficiales y memorias de gobierno, a modo de situar a la institución en el contexto general. Por último, también se incorporan publicaciones periódicas que fueron escritas por los mismos policías. Ante la distinta particularidad de las fuentes utilizadas se ha procurado mantener una visión coral de las prácticas abordadas.

\section{DE LAS COMPLEJIDADES Y RAMIFICACIONES DE LA BUROCRACIA POLICIAL}

Cuando parques nacionales, carreteras, cuarteles militares, y la explotación de petróleo, gas, hierro y carbón se afirmaban en el paisaje patagónico entre 1930 y 1945, la noción de "argentinizarla" se hallaba en pleno funcionamiento. ${ }^{1}$ Fuera de toda duda, el sur entusiasmaba como objeto turístico. Caminos pavimentados y líneas ferroviarias, hoteles emblemáticos y turistas comenzaron a ser vistos en los años treinta como avanzadas de nacionalización en las fronteras más lejanas, como puesta en práctica de la soberanía nacional (Ballent y Gorelik, 2001).

La atracción por la Patagonia ocupó a parte de los diputados, ministros, periodistas -como Roberto Arltque visitaron sus tierras. A decir verdad, ese interés llegó a ganar el primer plano de los discursos nacionalistas de entonces. Con las tensiones propias de un contexto de entreguerras, la policía, la Dirección de Tierras y la justicia letrada componían a ese Estado que distaba de ser ideal, en el imaginario nacionalista. El porvenir austral de excelencia era destino de las fuerzas armadas (Bohoslavsky, 2009; Ruffini, 2011).

Durante todo este período, sin embargo, la institución policial comenzó a dejar atrás su perfil de improvisación hasta dar a luz un proceso de burocratización, reorganización y profesionalización de sus filas cimentado en apercibimientos, saneamientos y purgas de empleados. ${ }^{2}$ Entre tales vaivenes convergió la Sección Orden Social en los primeros años de 1930. En Río Negro, la sección se (re)organizaría en diferentes momentos. Entre 1939 y 1945, Orden Social extendió sus competencias, denominándose Orden Social y Político. ${ }^{3}$ A cargo de esta dependencia se encontraba un oficial encargado junto a 8 agentes escribientes y 1 oficial de policía. ${ }^{4}$ 


\section{IMAGEN 1}

Revista Administrativa, No 81, marzo de 1945, p. 37.

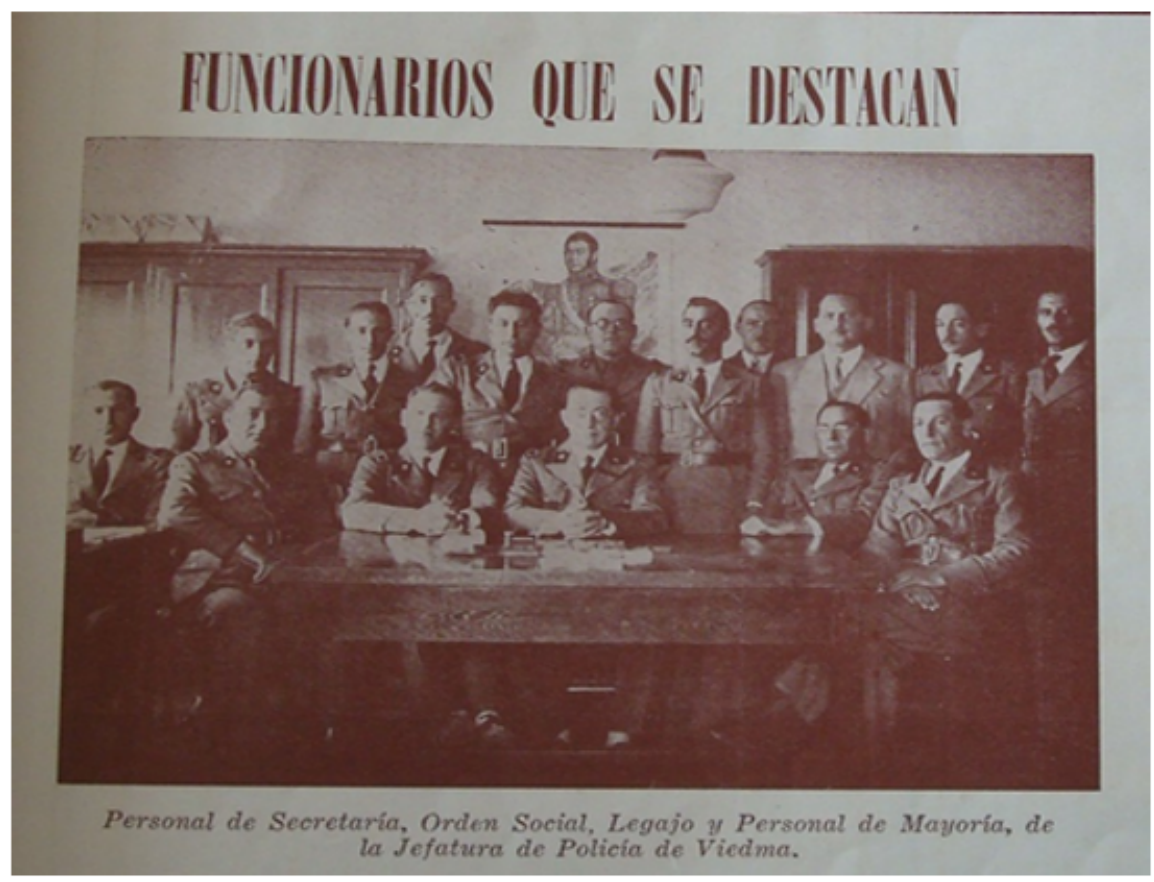

En adelante, los partes diarios de las comisarías remitidos a la jefatura además del apartado administrativas, delitos y accidentes, tendrían nuevos rótulos o títulos como División Investigaciones: Orden Social. Esta última sección incluía toda la información relevante y reciente sobre reuniones o asambleas realizadas o por realizarse. De tales eventos se informaban los horarios, los lugares, los temas tratados, las conclusiones extraídas y los nombres y algunas otras referencias sobre las personas que asistían. Cabe señalar que la mayoría de estos partes tienen en la parte superior de la hoja un sello en color rojo que indica Reservado.

En igual sentido, el cuerpo policial bonaerense transitaría un nuevo proceso de reformas que, direccionado en múltiples dimensiones, contempló fundamentalmente el reordenamiento de su organigrama. ${ }^{5}$ De acuerdo con lo observado por Barreneche (2019), el programa establecido en 1936, bajo la conducción de Pedro Ganduglia, delineó al interior de la policía el proyecto de modernización y centralización que el mandatario conservador Manuel Fresco promovía en el orden administrativo. En el diagnóstico de las autoridades con sede en La Plata, la situación abierta tras la "revolución septembrina"6 había acentuado la conflictividad política, sobre todo al interior del conservadurismo, aunque sin descartar la incidencia de otras agrupaciones partidarias excluidas o limitadas de la competencia electoral, como el radicalismo. Lejos de hacer posible el viejo anhelo de la autonomía, ello se tradujo, por un lado, en la inestabilidad de las cúpulas. Mientras que, por otro lado, supuso una mayor correspondencia de los subalternos en las tramas comunales de poder, tal como había acontecido durante el cambio de siglo.

De modo que, el afianzamiento del control sobre las distintas esferas del ámbito provincial ensayado por el gobierno conservador se interceptó en las transformaciones desplegadas en el tejido policial. Atender a esta vastedad de problemáticas exigía, principalmente, profundizar en sus instancias de profesionalización. En consonancia a las medidas de saneamiento destinadas a la oficialidad y tropa de las distintas secciones, las mejoras en el servicio se presentaban supeditadas a la renovación de equipamiento técnico, mediante la adquisición de armamento y automóviles, y, sobre todo, a la intervención articulada entre expertos y policías de facción abocados a la vigilancia de calles y campos, para complejizar los mecanismos puestos en práctica para la producción de información. No solamente por las exigencias de un escenario que se encontraba en permanente expansión, cuyo crecimiento urbanístico y demográfico tenía epicentro en el cinturón fabril 
que desde mediados del decenio 1920 trazaba el gran Buenos Aires (Gorelik, 2015), sino también ante el descrédito en el que sucumbían las policías, al ser concebidas de nuevo como el instrumento del caudillismo.

Ello supuso, a semejanza de lo señalado más arriba acerca de la experiencia territoriana, la reorganización y ampliación de las dependencias existentes. Que, espejadas en el modelo de la repartición metropolitana, definieron su especificidad acorde a las demandas internas y extrainstitucionales. Más que una sección novedosa, este pasaje indica un extenso recorrido que atañe a la especialización de sus funciones. ${ }^{7} \mathrm{La}$ incorporación de quien hasta entonces había presidido la División de Robos y Hurtos en la Capital Federal, el comisario Fernández Bazán, dinamizó entonces la División de Investigaciones.

\section{IMAGEN 2}

"Jefes de Secciones y Gabinetes de Investigaciones". Revista de Policía de la Provincia de Buenos Aires, Año II, No19, noviembre de 1942, p. 145.

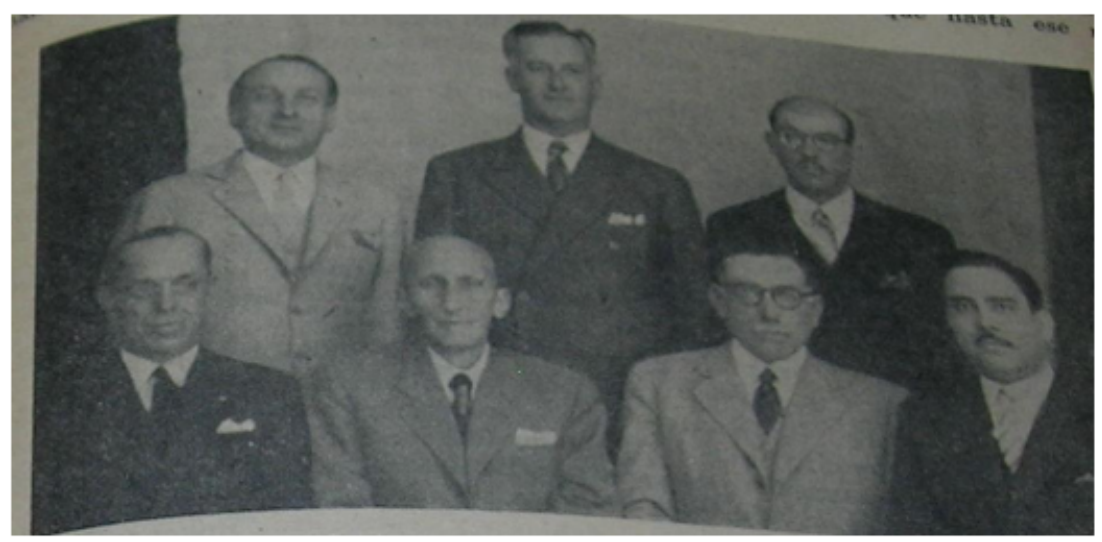

Un año atrás -1935- le había sido anexada la División Cuatrerismo. De igual manera, en el marco del proyecto de reorganización que el ejecutivo bonaerense implementaría sobre el cuerpo policial, se estipuló la jerarquización de la Oficina de Movimiento Político -dependiente de Investigaciones- con el objetivo de atender:

exclusivamente a la información diaria de los hechos normales y de la acción de los partidos políticos; velará por el cumplimiento de los edictos sobre reuniones públicas y examinará todas las formas de propaganda o publicidad que produzcan los diversos sectores en que se divide la opinión. Será, concretando, el medio de contacto de poderes públicos con la masa y las fluctuaciones del ambiente. ${ }^{8}$

En lo inmediato, la experiencia bonaerense quedaría opacada por sus limitaciones materiales, sobre todo. De acuerdo con una detallada semblanza de la Revista de Policía, al culminar 1938 se habían suprimido 200 plazas, entre oficiales, auxiliares y agentes. ${ }^{9}$ El gobierno de la intervención, acaecida en 1941, imprimiría un giro sobre la conducción institucional revitalizando, en primer término, el funcionamiento de la sección para someterla, en segundo término, a la tarea sostenida de contener los avances disruptivos del comunismo. Lo que implicaría ajustar sus mecanismos en torno a una órbita de colaboración interpolicial en la clave del escenario nacional.

En torno a ambas experiencias, es probable que las exhaustivas prácticas de investigación fueran entonces terreno de aceitados vínculos entre jefaturas, como así también, de circulación de policías. Como resultado de estas iniciativas, se favorecieron los canjes e intercambios de saberes policiales, que enlazaban los intereses provinciales con el nacional e internacional. Resumamos algunos hitos principales de estas conexiones para enfrentar los desafíos impresos por un contexto global, en el que gravitaban la posible expansión de un ciclo revolucionario -leído de manera alarmante en la posible ramificación de la III Internacional- pero principalmente, por el estallido de la Segunda Guerra. ${ }^{10}$ 
Las partículas de un nacionalismo difuso, cimentado en la discursividad patriótica y en la escenificación del tradicionalismo, permitieron precisar al menos en las cúpulas, tanto en la oficialidad como en los cronistas policiales, una noción más acabada del enemigo externo. En torno a ello, desde junio de 1941 y hasta el golpe de Estado del 4 de junio de 1943, la Comisión Especial Investigadora de Actividades Antiargentinas -creada por la Cámara de Diputados de la Nación-, se ocupó de investigar y combatir la penetración de ideologías extremistas en el país como aquellas de inspiración nazistas y fascistas. Durante los tres años de desarrollo a cargo del diputado Damonte Taborda, la comisión plasmó sus febriles diligencias en cuatro informes que se entregaron a consideración de la Cámara de Diputados de la Nación. Su funcionamiento se asentó, además, en la colaboración de los Ministros de Guerra y del Interior. Ambos ministerios debían coordinar las tareas desempeñadas por el ejército y la policía, respectivamente. ${ }^{11}$

Tan solo a un mes de su instauración, se efectuaba la Primera Conferencia en la Capital Federal entre los Ministros de Gobierno y jefes de policía de las provincias, jefe de policía de la Capital Federal y los gobernadores de los Territorios Nacionales. Con el objeto de coordinar medidas tendientes a prevenir y reprimir las actividades o la infiltración de ideologías contrarias al régimen de gobierno. En el artículo IV de las recomendaciones formalizadas y aprobadas en la conferencia, se proyectaba la creación de una sección dependiente del jefe de policía -de la ciudad de Buenos Aires, de cada provincia y Territorio Nacionaly de una autoridad de alta jerarquía, que se especializaría en los asuntos relacionados con las actividades comunistas, fascistas, nazistas, nacionalistas, extremistas y "toda manera de pretender infiltrar ideas o sistemas extranjeros, que mediata o inmediatamente pueden afectar la integridad o soberanía nacional” y donde deberían centralizarse las informaciones a los efectos del conocimiento, canje de antecedentes, etc. de los individuos o asociaciones objeto de tales imputaciones. ${ }^{12}$

La sección aludida clasificaría las actuaciones y comunicaciones que se recibieran en la jefatura y redactaría pedidos de informes o contestaciones. Asimismo, enviaría cuando fuere necesario testimonio de los antecedentes en poder de la oficina que pudieran ser de utilidad a cualquier autoridad policial del territorio o de la República, convenientes para el propósito perseguido de represión de tales actividades, y que pudiesen servir para el conocimiento de las mismas o iniciación de investigaciones. Sus agentes destinados a esta sección resumirían y compilarían las constancias que recibieran, abriendo un fichero con el nombre de la o las personas o entidades sindicadas de ejercer esas actividades. Vinculada con la División de Investigaciones se agregaría al prontuario de las personas vigiladas los originales o testimonios de índole necesaria. En la vigilancia permanente sobre las instituciones, clubes, asociaciones culturales, deportivas, mutualistas o sobre los vecinos o personas de tránsito que temporariamente arribasen al lugar, se solicitaría a las oficinas públicas y empresas particulares, "toda información confidencial de interés, ya sea sobre correspondencia, propaganda, giros”, entre otros, conveniente para el propósito indicial. ${ }^{13}$

Casi un año después del primer encuentro, dos eventos marcaron la agenda de criterios y procedimientos policiales en Argentina. De un lado, se llevó a cabo durante marzo la Segunda Conferencia de autoridades federales y provinciales para la vigilancia y represión de las actividades antiargentinas sobre la coordinación policial. De la cual se desprenderían las "Bases de Tucumán para un tratado de cooperación entre las provincias con la coincidencia de la Nación" y un protocolo adicional, celebrado entre el 8 y 11 de julio en dicha ciudad. ${ }^{14}$

Para la aplicación de estas medidas, cada provincia o territorio conservaría totalmente sus regímenes y procedimientos propios en materia policial. Se anudaba a la serie de prescripciones, aquella habitual aspiración de profesionalización de sus fuerzas. En los espacios donde no existieran, se debían crear escuelas para la preparación de los funcionarios y empleados policiales de carrera.

La empresa quedaría completa con la redacción del protocolo adicional que definía las líneas principales en cuanto a: 1) la imperiosa necesidad de comunicación directa al interior de cada policía de las jurisdicciones como con los representantes de Gendarmería Nacional y prefectura General Marítima, vía radiotelefónica y radiotelegráfica; 2) en caso de ser requerido el gobierno federal subvencionaría la instalación de estaciones 
transmisoras; 3) en torno a cada una de estas secciones especiales se encadenaba un organismo coordinador denominado "Oficina Policial Argentina" que tendría a su cargo la regulación de las funciones asignadas en el tratado y en la creación de un fichero central que se nutriría de los aportes de cada delegación referidos a datos y antecedentes relativos a personas, asociaciones, institutos, círculos y otras entidades sospechosas de actividades antiargentinas. ${ }^{15}$

Como ecos multiplicados de las dos reuniones precedentes, entre el 27 de mayo y 9 de junio de 1942 se desarrolló la Conferencia Interamericana sobre Coordinación de Medidas Policiales y Judiciales, realizada en Buenos Aires. ${ }^{16}$ Organizada por el Consejo Directivo de la Unión Panamericana, bajo acuerdo en la III Reunión de Consulta de los Ministros de Relaciones Exteriores de las Repúblicas Americanas, se expresaba que:

(...) la situación de guerra producida (...), obligan a anticipar la conferencia proyectada porque las medidas tendientes a coordinar la defensa nacional contra espionaje, sabotaje, traición, sedición y otras actividades ilícitas o subversivas, lo mismo que la cooperación interamericana para la coordinación de los sistemas establecidos en cada Estado sobre identificación de personas y anotación de antecedentes, para la concertación de reglas y procedimientos relativos a la comunicación de sentencias judiciales y para el cumplimiento de solicitudes de extradición, de diligencias probatorias y de expulsión de extranjeros, según el programa aprobado por la Unión Panamericana, exigen que se ponga de inmediato en ejecución. ${ }^{17}$

El acta de la aludida Reunión de Consulta, recomendaba asimismo, que en dicha Conferencia se estudiara la posibilidad "de ampliar el Convenio Sudamericano de Policía, suscrito en la Capital argentina el 29 de febrero de 1920, en forma de que sus disposiciones sean aplicables a todos los países del Continente y de incorporar en dicha Convención la creación de un "Registro Interamericano de Prontuarios Policiales". ${ }^{18}$ Que permitiese, de igual modo, la identificación de los individuos procesados o condenados en otros países americanos, por delitos internacionales y actividades subversivas dirigidas, individual o colectivamente.

Los servicios de inteligencia e investigación fueron considerados también por los Ministros de Relaciones Exteriores. Los gobiernos americanos debían coordinar sus propios sistemas nacionales creando organismos que favorecieran el intercambio de informaciones, investigaciones que, a su vez, garantizaran "prevenir, reprimir, castigar y eliminar las actividades de espionaje, sabotaje e incitación peligrosas para las naciones americanas" ${ }^{19}$ De manera que, el objeto de la Conferencia era preparar tratados y recomendaciones que se estimaran necesarias para asegurar la coordinación de la acción de los Estados con la de todas las naciones americanas. $^{20}$

Por el grado superlativo de los proyectos, se presume que las interacciones, programas y dispositivos federales como panamericanistas de vigilancia y circulación de información configuraron sentidos y prácticas de control policiales donde anudar los hilos más dispares de todas las vertientes de investigación y persecución, que persistentes o resurgidos, convergían en la Argentina de los años treinta y cuarenta.

A esa evidencia de cooperación interpolicial provincial y panamericana, habría que sumarle además el hecho de la colaboración de otras fuerzas de seguridad como Gendarmería Nacional. De momento, al menos desde su creación por el Congreso Nacional, se dejaba claro que la gendarmería tenía un amplio carácter de policía militarizada federal bajo la dependencia del Ministerio del Interior. Pero pasaba a depender del Ministerio de Guerra cuando "fueren menester movilizarlas para reprimir actividades que pusieran en peligro las instituciones del país y la estatalidad de su gobierno constitucional, o sea, por actos calificados de sedición, rebelión y huelgas de carácter extremista". ${ }^{21}$ A esta fuerza, en 1942, se sumó con mayor presencia el Ejército en guarniciones organizadas en las gobernaciones del sur (Río Negro, Chubut, Santa Cruz y Tierra del Fuego), como respuesta a "las necesidades urgentes de la defensa nacional". ${ }^{22}$ Dos años más tarde, en julio de 1944, el decreto 15.385/44 dictado en acuerdo de ministros y el Consejo de Defensa Nacional, auguraba la creación de "zonas de seguridad del interior", "zonas de seguridad de frontera" y de una "Comisión Nacional de Zonas de Seguridad" destinadas a complementar las previsiones territoriales de la defensa nacional. ${ }^{23}$ 
En territorio rionegrino, en particular, coexistían distintas fuerzas: la Policía territoriana y la Federal, la Gendarmería y el Ejército. Las acciones de información e investigación tenían un claro nexo entre cada una de ellas. El siguiente caso exhibe los vínculos informativos entre estas agencias. El 9 de febrero de 1943, el Ministerio de Guerra se dirigía al comandante de la Agrupación Bariloche (Ejército), por una nota recibida por intermedio del Ministro del Interior, sobre un acto propiciado el 26 de diciembre de 1942 por Acción Argentina. ${ }^{24}$ Se le solicitaba a aquella División "recabar un informe". ${ }^{25}$ Desde la institución policial se tenía conocimiento exhaustivo tres días después del acto gracias al informe del oficial de policía, José Moral, elevado al jefe de la repartición y reenviado al Ministerio de Guerra. El evento se celebró en el Cine Central, patrocinado por la agrupación mencionada. Para difundir el acto se había apelado al periódico Bariloche, cuyo director, E. S., estaba sindicado como comunista. Propaganda que "había arrastrado" a un gran público de ocupación obrera. Se unieron al convite, la mayoría de los empleados de la intendencia de Parques Nacionales citados, especialmente, por el intendente local. El total de asistentes rondaría las trescientas cincuenta personas.

Al detallar sobre la conferencia, el oficial informante señalaba que "degeneró virtualmente en una apología del régimen soviético. Se habló de reivindicaciones sociales, se vivó estruendosamente a Stalin y lo más grave del caso, se agravió insolentemente al actual gobierno de la República" ${ }^{26}$ En este último punto, las críticas se focalizaban en el primer mandatario al "prohijar ideas totalitarias" y sumergir al país en la "bancarrota" con su pretendida neutralidad. La gendarmería, continuaba describiendo el policía, asistió impasible ante los vocablos "hirientes, insolentes y soeces con que se endilgó al gobierno nacional". Solamente prohibió la mención de nombres propios cuando se hablaba de los señores Hitler y Mussolini. ${ }^{27}$

El oficial adicionaba como registros de la reunión la tendencia que albergaban los altos jefes de las fuerzas armadas a ideas totalitarias y su identificación con una posible absorción por parte de esos países. Sin embargo, se destacaba que en el acto el empleado de parques nacionales, Nicolás Miñervini, había manifestado al intendente local de dicho organismo su disconformidad por su apoyo incondicional a la realización de esa jornada y por no intervenir ante los agravios vertidos al gobierno nacional; sin que tuviese un gesto de repudio a los dichos o "desmanes orales". Por último, el informante señalaba las represalias que sufrirían dicho empleado y todos aquellos que hubiesen desoído la invitación.

Claro que todo esto implicó una serie de informes y notas secretas y reservadas dentro del Ejército. Así contaba la información dirigida, el 18 de febrero de 1943, al Comandante de la Sexta División del Ejército por parte del Teniente Coronel Jefe de la montaña y Agrupación Bariloche, Napoleón Irusta; quien señalaba la ausencia de noticias del evento por parte de Gendarmería y que se había enterado por amistades cercanas. De modo que solicitaba detalles al Segundo Comandante de gendarmería, Santiago Grau. ${ }^{28}$

Para finalizar, transmitía lo expresado por el Comandante de Gendarmería, Arturo Cardoso, sobre la realización de futuras conferencias de carácter político en los días próximos; autorizadas por el Gobierno del Territorio. Advertía que eran contraproducentes para la tranquilidad de la población y sugería se dispusiera evitar tales actos. En cuanto al director del periódico E. S., referenciaba que sus publicaciones eran "izquierdistas, promoviendo con ellas el levantamiento de la masa obrera y molestando a la gente trabajadora".

En otro documento adjunto, el Teniente Comandante del Ejército indicaba que un día después de ese acto, se habían reunido nuevamente simpatizantes de Acción Argentina para conformar la comisión local. Pese a todo lo informado, concluía que tanto las conferencias como estas reuniones no habían provocado "ningún movimiento de opinión (...) ni se ha recogido que tales actos hayan influido ánimo de protesta o disconformidad, sino solamente comentarios o alusiones sin trascendencia”. ${ }^{29}$ Sin embargo, destacaba que en los próximos meses su jefatura a cargo de Agrupación Bariloche prestaría especial atención a todas estas actividades.

Casi veinte días después del pedido de informe, llegaba el expediente producido por el Jefe Militar de la Agrupación Bariloche, que sería remitido a Auditoría General de Guerra y Marina para emitir su opinión. 
En el dictamen se resaltaba que expresiones agraviantes habían sido vertidas en el acto de Acción Argentina sobre el Presidente de la República sin que los representantes de Gendarmería Nacional presentes tomaran intervención. Y luego continuaba planteando que del informe del Comandante Arturo Cardoso no se desprendían tales insultos a los que aludía la policía.

Respecto a las actividades que el expediente narraba y las medidas que se debían adoptar, eran competencia del Ministerio del Interior. Desde el punto de vista militar, "solo interesa en estas actuaciones establecer si el informe del comandante del escuadrón Bariloche se ajusta a la verdad, para en caso contrario, hacer efectiva la responsabilidad disciplinaria pertinente" ${ }^{30}$ Para tal efecto, el auditor solicitaba al Director General de Gendarmería Nacional ordene una investigación para esclarecer la situación.

De acuerdo a lo dictaminado, se designaba desde Gendarmería al Juez de Instrucción Militar, Enrique Velloso, para investigar la exactitud de los hechos. De su viaje en ferrocarril a Bariloche, el investigador pudo recabar que el informe presentado por el oficial José Moral no había sido confeccionado por él, ya que según los testimonios del personal de gendarmería no había concurrido al acto. En su lugar había otro oficial, Alberto Franco (adscripto al Escuadrón de Gendarmería). En su declaración José Moral continuó afirmando que había redactado el informe, mientras algunos testigos daban cuenta de que ese día se hallaba en Pilcaniyeu. En consecuencia, el juez de instrucción militar-investigador llegaba a la conclusión de que el policía había obrado con "intenciones premeditadas pues los datos y referencias que dicho informe consigna no son el resultado de una percepción personal; pues dicho oficial en ningún momento estuvo presente en el acto". ${ }^{31}$

Para finalizar, de la investigación se probaba que el accionar del Escuadrón de Gendarmería había sido correcto y "con la energía que el caso demandó". Además, se alertaba al Ministerio de Guerra la importancia de dar a conocimiento del caso al Ministerio del Interior. El expediente concluye con el sello de la Jefatura de Policía de Río Negro recepcionando el informe. El documento anuncia entonces una articulación de oficinas, ministerios e instituciones en materia de investigación. Sin embargo, esta conjunción entre agencias estatales no estaba exenta de recelos y desconfianzas. Una trama que exterioriza las acciones desempeñadas por unos y otros, como aparenta el cierre de este caso.

\section{EL DESPLIEGUE EN LAS CALLES: LA RECOLECCióN Y PRODUCCIÓN DE INFORMACIÓN}

Resta examinar el segundo punto anunciado, el problema de un conjunto de saberes y expertos para la búsquedy condensación de datos. Digamos, para empezar, que centralizar e integrar información clasificada era el resultado de las investigaciones policiales desarrolladas en el terreno. Averiguación de información, seguimientos, infiltración de agentes constituían una faceta más del acecho policial. Lo importante fue ocuparse de imponer una discreta vigilancia sobre las entidades culturales y políticas en los espacios, aunque hubieran sido clausuradas.

En los tempranos años cuarenta, el Jefe de la División de Investigaciones de Río Negro, Argiroffi, comunicaba que "la carencia de personal especializado (...) dificulta una acción más coordinada y perfecta, no obstante lo cual el problema se considera dominado por las precisas y bien comprendidas directivas que renovadamente se imparten a los funcionarios del interior, por medio de esta oficina". ${ }^{32}$ De manera que, en ese panorama había una disparidad de recursos y saberes de cuya tensión irresuelta se desprendían las prácticas radicalmente nuevas.

Para la experiencia territoriana no existirían escuelas de formación hasta 1948. De allí que las instrucciones eran efectuadas de manera individualizada según la experticia y trabajo que realizaba cada empleado. Por ese tiempo algunos policías rionegrinos participaron de una especialización en la División de Investigaciones en la Policía Federal. Como el caso de Delfor Cruz, quien fue designado integrante de la delegación policial del territorio, destinada a la Capital Federal, para seguir cursos a cargo de la sección especial de investigaciones, en la coordinación de la represión del comunismo en todo el territorio de la nación (Fernández Marrón, 2017). 
Descripciones de agentes entrenados en estas actividades recuperan y confirman la idea de que existía en las policías estudiadas una cierta profesionalización. Podemos vislumbrar algunos de esos momentos en la carrera de Agustín Galissier. En junio de 1946, el subcomisario se dirigía al Presidente de la Nación, J. D. Perón, para exponer las persecuciones cometidas en su calidad de funcionario público como instructor de sumarios en actividades contrarias al gobierno de E. Farrell y que le impedían avanzar en su carrera policial. ${ }^{33}$ Dos años atrás, a raíz de "movimientos de opinión y actividades políticas" en Villa Regina (Rio Negro) ${ }^{34}$ "que mantenían en constante perturbación a los distintos sectores de la población y colonia", el gobernador Lebrero encomendaba una investigación. Agustín Galissier por entonces se desempeñaba como Secretario de la Jefatura de Policía. Teniendo en cuenta que era "ajeno al vecindario, estar despojado de toda vinculación política y por otra parte haber demostrado su lealtad hacía las autoridades que regían el destino de la Nación”, colaboró en la pesquisa junto a otros cuatro funcionarios policiales. ${ }^{35}$

En el curso de la investigación, se recabó información que responsabilizaba como "los principales causantes de desórdenes sociales y alteración de la paz interna" al director de escuela A. H., al inspector y representante del Banco Hipotecario Nacional J. Q., al odontólogo M. P. y al administrador del establecimiento agrícola Gutiérrez E. D. Los cuatro fueron individualizados como "elementos de perturbación social y derrotistas de la obra de gobierno de la Revolución del 4 de junio; (...) que no vacilaron en prestar su concurso moral para estimular la acción de elementos de documentada filiación comunista y anarquista, fertilizando así el campo ideológico de la izquierda." Todos fueron detenidos y puestos a disposición del Ministerio del Interior. Aunque en los primeros días de agosto de 1944 fueron liberados.

Semanas más tarde, inscripciones en la capilla, puentes y muros locales volvían a vincular a los ex-detenidos como autores de las injurias: "Muera Perón, asesino y frailón”, "Abajo el militarismo asesino y bárbaro", "Viva la anarquía, muera Perón", "Mueran los militares", "Libertad presos Regina”, "Muera la dictadura de la espada y la cruz", "Abajo la religión", "Viva el comunismo libertario". A pesar de que no volvieron a ser apresados, continuaron siendo investigados. El 9 de septiembre, Agustín Galissier "en misión oficial” con otros agentes entre los que se encontraba el mencionado Delfor Cruz-, en Capital Federal redactaba y elevaba un acta sobre los vínculos de los ex-detenidos con la maestra exonerada, Ida S., de "documentada actividad y sentimientos comunistas”. El informe había sido labrado en la Sección Especial de la policía porteña. ${ }^{36}$

En su foja de servicio consta una antigüedad de 8 años de servicio como subcomisario y 16 en la repartición policial. Agustín Galissier se había iniciado como agente meritorio en 1931, a la edad de 24 años. ${ }^{37}$ Había sido designado a seguir cursos en la Sección Especial de la División de Investigaciones de la Policía Federal, en la coordinación de represión a las actividades contrarias al gobierno nacional. También había integrado como jefe una comisión compuesta por miembros de gendarmería nacional -que con conocimiento de las autoridades militares del Regimiento 5 (Bahía Blanca)-, ejecutaron procedimientos en la Provincia de Buenos Aires, de los que se detuvieron “a numerosos elementos contrarios al gobierno”. Mientras que, se había desarrollado de forma continua como instructor de sumarios "tendientes a la comprobación y represión de actividades antiargentinas de extrema izquierda". ${ }^{38}$

Como testimonio de esa formación en otras reparticiones, los agentes bajo la órbita de la Sección Orden Social -y político más tarde- se ocuparon, entretanto, de motorizar toda una batería de prácticas de información. En sus seguimientos cotidianos de los opositores, los policías pertenecientes a la División de Investigaciones estaban sujetos a ciertas reglas: "a) vestirá de civil, b) no será saludado en la vía o lugares públicos por el personal uniformado, c) podrá ausentarse de la Capital por asuntos de servicio previa comunicación a la superioridad, d) acreditará su condición con la credencial respectiva, e) cuando efectúe un procedimiento por orden superior o por propia iniciativa será considerado en comisión reservada, a fin de que su acción no se interrumpa o desnaturalice, y ningún superior de otra dependencia podrá interrogarlo o hacerle indicaciones, debiendo limitarse a dar cuenta de las faltas que aquel cometiera en el desempeño de sus funciones." ${ }^{39}$ Pese a ser tan evidente la presencia policial poco es lo que podrían resguardar el anonimato 
en ciudades y pueblos pequeños donde todos se conocían y prevalecían las relaciones cara a cara. Se trataba de pequeñas poblaciones, donde una gran parte de los habitantes vivían en la zona rural.

Frente al despliegue policial, por ejemplo, en Río Negro habían sido clausuradas y disueltas "aquellas entidades sociales y políticas, así como gremiales que en la práctica servían a la causa comunista, tales como Acción Argentina, confederación democrática argentina de ayuda a los pueblos libres, sindical argentina de ayuda a los pueblos libres, sindicatos obreros". ${ }^{40}$ Según se describe en el siguiente telegrama, enviado por el secretario de la gobernación al Ministro del Interior, Miguel Culaciati:

La jefatura de policía ha remitido a la gobernación las actuaciones promovidas con motivo del allanamiento del local del Sindicato de Obrero de la Construcción de San Carlos de Bariloche, de cuyo procedimiento y prosecusión se informó a V.E. Como consecuencia del procedimiento hallánse detenidos Arturo A., Justo Germán O., Juan Antonio N., Estebán S., Milenko I. y Celmiro R. principales dirigentes del precitado organismo, sindicado como foco de propagación de actividades extremistas. Por si fuera del caso considerar si la acción se halla al margen de la ley y a los efectos de las sanciones que se crea oportuno a los detenidos, quedan ellos alojados en la comisaría de esta ciudad a disposición de V. E. ${ }^{41}$

De todas las medidas, las reuniones políticas y públicas fueron las que sin dudas merecieron tratamiento. Un interés creciente pasó por supervisar y autorizar todo tipo de reunión. Dentro de las múltiples facultades, la policía podía acceder a los locales cerrados como a los espacios públicos donde se desarrollaban las actividades.

Las observaciones y rastreos realizados durante semanas, años a personas y organizaciones de la sociedad civil, en ocasiones, eran la antesala al allanamiento, y a partir de precisar los antecedentes negativos que tenían los sospechosos, consumar la detención. Al problema generado por ser detenido y llevado a alguna de las dependencias policiales, se sumaba el ciclo de interrogatorios por el que transitaban los considerados "peligrosos". Con la curiosidad que despertaban estos casos, la policía aprovechaba para incautar correspondencia, libros "subversivos", panfletos, propaganda y otros elementos que permitieran reconstruir la circulación de lecturas y dotarlos como prueba indiciaria. ${ }^{42}$

Para el período estudiado, los expertos que se abocaron a la conformación de archivos, la elaboración de prontuarios, la identificación dactiloscópica, entre otros procedimientos, formaban parte de la División de Investigaciones. ${ }^{43}$ En el caso bonaerense, en su capital y zonas aledañas, desde la década de 1910 se contaba con un sistema de fichado que posibilitó el armado de un archivo de "delincuentes peligrosos" y de "agitadores indeseables" una vez apresados; conformado de fichas particulares en la que se plasmaban las huellas dactilares.

El reservorio de información que se resguardaba en el Archivo General de Prontuarios detalla sistematizadamente los antecedentes de cada conflicto y los nombres de sus protagonistas. Concentrar, organizar y coordinar la información permitiría que mensualmente la División de Investigaciones elevara una estadística de la labor realizada. En íntima conexión entre la Sección de Identificaciones y la Sección Orden Social, el esquema vinculaba la plasmación y mesura de las impresiones dactilares denominadas simples y una de canje - para intercambiar con otras dependencias- con la narración del prontuario. Al compás de la deriva impuesta por las investigaciones, entre los documentos generados, la redacción de los prontuarios proporcionaba un instrumento adecuado para la consulta ágil, de amplia y libre disponibilidad entre los policías de la última dependencia. Estos documentos se constituyeron como punta de lanza para conocer al "enemigo". Bajo el formato de cuadernillo impreso el prontuario permite, por un lado, asomarse al perfil social y laboral del sospechoso, por otro lado, realizar una reconstrucción sociodemográfica (nacionalidad, edad, instrucción, estado civil, cantidad de hijos, etc.). Por último, conocer el itinerario hacia el interior de la institución a partir de los procesos y arrestos sufridos.

Toda esa cantidad de información recolectada en un repertorio ordenado con todos los datos referidos a todos aquellos opositores que habían sido objeto de investigación, permitían que, tal como se expresa a continuación: 
tras empeñosas investigaciones practicadas a partir de agosto de 1943, se logró la comprobación de que en distintos pueblos del territorio, tales como Cinco Saltos, Cipoletti, General Roca, Allen, Villa Regina, Río Colorado, Ing. Huergo, Viedma y San Carlos de Bariloche, se intentaba una propaganda extremista dirigida por el partido comunista, procediéndose al secuestro de abundante material de divulgación y la individualización y detención de cincuenta personas comprometidas por esas mismas actividades, las que fueron oportunamente puestas a disposición del gobierno nacional y algunas de las cuales recobraron más tarde la libertad condicional. ${ }^{44}$

Con la finalidad de agilizar la compilación y el acopio de información se efectuaron distintos mecanismos que respondían a una política nacional como el Registro Nacional de Personas al servicio de entidades extranjeras a cargo de la policía federal (decreto PEN 21764/44); y en algunos casos, implementados por el Ministerio del Interior solo en los Territorios Nacionales como un censo de la población extranjera, Registro de sociedades, un fichero especial de prontuarios, carpetas para la conservación de asuntos y distintas instrucciones a las dependencias para la fiscalización de los organismos, las colectividades extranjeras e individuos sindicados como elementos de tendencia disolvente. ${ }^{46}$

\section{UNA GENEALOGÍA DE LOS SENTIDOS DE LOS "PELIGROSOS"}

Después del golpe de 1930, las funciones de seguimiento e información se acentuaron contra los partidos y movimientos políticos opositores al régimen, como así también sobre maestros, periodistas y obreros. Esta labor desplegada coincidió con una convicción arraigada en muchos funcionarios de otras policías del país acerca del carácter esencialmente represivo de la institución, que se focalizaría sobre diversos grupos concebidos como "peligrosos" y cuya configuración se fue cimentando desde los comienzos del decenio, para confluir en la polisémica categoría de terroristas de uso cada vez más constante en la policía bonaerense.

Ello integró, en distintos momentos, a una población itinerante, mayormente desempleada y golpeada aún por los efectos de la crisis junto a las fracciones del radicalismo "personalista", proscripto de los comicios tras el derrocamiento de Yrigoyen y pasible de alzarse en armas; el anarquismo más bien fragmentado y focalizado en determinadas organizaciones sindicales, junto a un segmento del Partido Socialista desplazado de las coaliciones gubernamentales que impulsaron la candidatura presidencial de Justo. A este significante se añadiría, y por la envergadura de su carácter transnacional, la peligrosidad encarnada por el Partido Comunista. Cuya represión constituiría uno de los puntos nodales de la agenda desplegada por las secciones de Investigación (Marengo, 2012).

En este sentido y más allá de las derivas que supuso en el marco de la década del treinta la consolidación de un modelo autoritario de poder, con sus ritmos y variantes locales, la centralidad que fue adquiriendo el comunismo en tanto "ideología perniciosa" -en una visión compartida por los elencos dirigentes y policías-, permite redefinir otra cronología que matiza los recortes más homogéneos con los que se ha observado al período. Al tiempo que, en un primer momento como abordaremos seguidamente, sus referencias operaron en tanto categoría catalizadora que remitía sin demasiadas especificidades a los actores partidarios, sociales e intelectuales antes mencionados.

Los años de entreguerras, para los espacios rionegrino y bonaerense, estuvieron signados en buena parte por la conflictividad obrera y una mayor presencia pública de las asociaciones vinculadas al mundo del trabajo. Operarios de las zonas valletana y andina de Río Negro, protagonizaron huelgas por reivindicaciones salariales y mejores condiciones laborales, que se exacerbaron sobre todo debido al impacto agravante de la crisis económica (Rafart y Mases, 2003). Si bien este rasgo fue también notorio en el área pampeana, la acción sindical no alcanzaría la capacidad de articulación territorial obtenida a comienzos de siglo por las entidades ácratas, aún a pesar de las ramificaciones alcanzadas por la huelga general de 1936 (Ascolani, 2013). Para la minucia policial incluso, resulta notoria la estabilización de la protesta social en los años inmediatamente anteriores a 1930. Claro que a escala local y de acuerdo al nivel de especialización de sus principales actividades productivas, diversas experiencias de organización obrera pervivieron bajo la conducción de la FORA, 
como en la industria marplatense del pescado (Nieto, 2018). Más que la necesidad de satisfacer demandas ancladas a estos ámbitos, el ciclo de movilizaciones proletarias durante el traspaso de las décadas se estructuró principalmente en las campañas de solidaridad internacional por Sacco y Vanzetti (Suárez, 2013b) para extenderse con una gravitación cada vez más debilitada, en el caso bonaerense, ante las reverberaciones del proceso de Bragado (Jordán, 1988).

En gran medida, fueron las posturas antiautoritarias que concitó el régimen consolidado con Uriburu las que fortalecieron las acciones de lucha colectiva, de igual manera en que se acentuaron las respuestas represivas a cargo de las fuerzas policiales. A la persecución de militantes anarquistas como socialistas bajo las disposiciones emanadas del estado de sitio, se añadió la vigilancia y hostigamiento sobre los agrupamientos radicales de extracción hipolista, que comenzaron a ser percibidos como disolventes tras su intento de saltear la proscripción a la que habían sido sometidos luego de la anulación de las elecciones de 1931 (Béjar, 2005).

Amalgamados a las representaciones disponibles de lo que el anarquismo había significado, la División de Investigaciones principalmente y en colaboración con otros cuerpos especializados y las policías de facción procedieron a comienzos de 1933 a desactivar en distintos puntos de la provincia -Avellaneda, General Belgrano y Olavarría- el movimiento insurreccional que se articularía con el levantamiento radical de Corrientes, identificando a los "conspiradores" como "rebeldes y sediciosos". ${ }^{46}$ Dichas conexiones se solidificaron incluso en las figuraciones construidas en torno al affaire de Bragado, ya que algunas voces del oficialismo reconocieron en el atentado de evidente signo ácrata el punto de partida para el complot que aquéllos junto con socialistas, militares disidentes y afiliados de la FORA gestarían para derrocar al presidente de facto (Jordán, 1988).

Si bien la organización como las ramificaciones del Partido Comunista tuvieron en la provincia una temporalidad sinuosa, del mismo modo en que resultó minoritario su alcance en las conducciones gremiales -en muchos casos con primacía aún anarquista o debiendo competir con los influjos de la incipiente Confederación General del Trabajo-, la circulación de sus delegados fundamentalmente en el cinturón industrial del gran Buenos Aires, conllevará al refuerzo del cuerpo de policía y en particular de la División de Investigaciones para identificar y pautar el seguimiento de posibles "agitadores" que atentasen contra la libertad de trabajo. De esta manera, la interpelación de senadores bonaerenses de la bancada socialista, durante los primeros meses de 1934 al Ministro de Gobierno Vilgre Lamadrid, revela, en primer término, una multiplicidad de indicios acerca del accionar que los miembros de esa repartición mecanizaron para la represión de las ideas comunistas y sus agentes en torno a la cultura obrera. Así como nos permite recomponer de manera inferencial, en segundo orden, cuáles eran los sentidos con los que la dirigencia conservadora y nacionalista compuso una visión sobre el comunismo, que se transferiría a modo de legitimación de la represión ejercida por los efectivos policiales.

La detención del delegado de la Unión Obrera Textil, Juan Armendáriz, en los lindes de una planta del rubro situada en Quilmes, durante un plan de lucha en el que oficiaría como mediador ante el Departamento de Trabajo, suscitó un pedido en el marco de la Legislatura bonaerense por el que se solicitaba al Ministro informe sobre la existencia de una sección policial denominada "Contra el Comunismo" y de quiénes la componían. La contestación de éste, presentada en un detallado escrito, reafirma la ramificación dentro de la División de Investigaciones del "Gabinete de Orden Social y Comunismo", compuesto exclusivamente por empleados especializados y no por personal de tropa,${ }^{47}$ cuya función específica era la de:

efectuar las averiguaciones tendientes al esclarecimiento de los delitos de orden social y gremial (atentados a la libertad de trabajo, actos subversivos de carácter anárquico, etc. ${ }^{48}$ ) y atender a la vigilancia preventiva en caso de conflictos entre patrones y obreros, o sus derivados a fin de evitar hechos punibles actuando únicamente en tales casos el personal del Gabinete Orden Social y Comunismo como colaborador en la acción que desarrolla la policía de seguridad. En cuanto a la segunda parte de la denominación de ese Gabinete, sólo se refiere al comunismo cuando éste adquiere carácter y violencia o atentatorio contra el orden y la seguridad colectiva. ${ }^{49}$ 
De acuerdo con lo aquí consignado, la praxis política e ideológica que definía al comunismo era concebida por los legisladores y autoridades ejecutivas como una expresión de extrema radicalidad, cuyos fundamentos se sostenían mediante el ejercicio de la violencia. Caracterización que, a su vez, posibilitaba asociarlo desde una absoluta linealidad con el anarquismo. Ello se cristaliza, por ejemplo, en la interlocución del senador Obregón del gobernante Partido Demócrata Nacional al desestimar las denuncias proferidas por sus pares socialistas, señalándole su:

apología del comunismo, del anarquismo y del terrorismo, (reconociendo) no solamente la concomitancia con ellos, sino cierta identificación por la larga exposición doctrinaria y la calurosa defensa hecha de los principios, de los dogmas y del sectarismo comunista. Nos decía que el comunismo no tiene caracteres de criminalidad, pero basta recorrer las crónicas policiales de los diarios para encontrar que los más grandes hechos delictuosos, los mayores atentados a la propiedad y a la vida, han sido realizados por elementos catalogados como comunistas, anarquistas y terroristas. ${ }^{50}$

En torno al otro aspecto que hemos señalado, acerca del accionar de los integrantes de la División de Investigaciones, de acuerdo a las denuncias proferidas por los legisladores que recabaron el testimonio de Armendáriz, su intervención permite constatar un repertorio de prácticas que trascienden a la mera situación de vigilancia. Si bien por disposición de la División Administrativa y como resultado de la instrucción llevada a cabo en la justicia de primera Instancia, la Jefatura de Policía resolvió la exoneración de los oficiales y agentes supeditados al operativo. No obstante, en su apresamiento efectuado de manera ilegal el delegado fue conducido inicialmente a la comisaría local sufriendo permanente agresiones físicas por parte de los pesquisas. Aunque luego sería trasladado a las dependencias de la División de Investigaciones, en la ciudad de La Plata, donde -de acuerdo con su relato- se lo llamó:

a la oficina de identificación, se me hizo una fotografía, se labró una exposición en la cual se hacía constar de que todas las lesiones que yo presentaba me las había producido solo, aconsejándome que me convenía firmar eso a los efectos de poder recobrar la libertad inmediatamente (...) Se me tomaron las impresiones digitales, fotografías, etc., y pude leer en la boleta que se hacía constar mi condición de comunista. Protesté aduciendo mi condición de viejo militante socialista, contestándoseme que eso no tenía importancia consumiéndose después al calabozo. ${ }^{51}$

Pero más allá del recorrido por estas instancias burocráticas, resulta llamativo que, durante el traslado desde el destacamento de Quilmes hacia la capital provincial, el automóvil en el que era conducido fue desviado hacia zonas descampadas próximas a las vías del tren, donde el personal a cargo le infligió una golpiza. ${ }^{52}$

Esta aproximación, tan indefinida y polivalente de distintos actores sociales y políticos observados de peligrosos a lo largo de los años treinta, preparó y recuperó en la forma una nueva axiología comunista. Principalmente, porque para mediados de la década, partido e ideología serían precisados de manera taxativa en tanto amenaza exógena. Despejándolos, igualmente, de las referencias totalizadoras que lo emparentaban con las fuerzas partidarias y culturales acusadas de cuestionar radicalmente la estabilidad social. ${ }^{53}$

El fortalecimiento transnacional de los posicionamientos antifascistas, en los umbrales de la segunda guerra, reforzó sobre todo en los efectivos policiales la necesidad de extremar la vigilancia sobre las posibles filtraciones del "enemigo comunista", solapado en campañas de solidaridad que recorrían diversos puntos del mapa nacional concitando adhesiones por los exiliados de la República española como la condena hacia las potencias del Eje. Ello se combinaría, asimismo, con la vigorización represiva que las autoridades de las intervenciones federales, desde 1940, a cargo de las Fuerzas Armadas le imprimirán a las conducciones policiales.

En la Provincia de Buenos Aires, sobre todo, aunque la permanencia al frente de la repartición fue más bien inestable, se sostuvo el accionar represivo cimentado desde mediados de la década anterior hasta su extensión mediante los convenios interpoliciales expresados en la "Campaña Antiargentina", exhaustivamente abordada más arriba. Dada la adscripción ideológica que las diversas Jefaturas precisaban en torno al materialismo economicista profesado por los "agentes moscovitas", se diseccionaba en sus discursos anticlerical como antimilitar el rasgo más prominente de su carácter antinacional y subversivo. Aspecto 
nodal en un contexto signado por la centralidad creciente de la iglesia católica en la sociedad rioplatense de entreguerras (Lida, 2009), así como de consolidación de las fuerzas militares en tanto actor de poder.

Para la experiencia territoriana, de igual modo, el sumario por faltas como funcionario público al director de sanidad vegetal, C. Gutiérrez, en 1941, probaría esta vertiente de significados más claramente transmisibles y aplicables en las investigaciones policiales. De Villa Regina, arribaba una carta al Ministerio del Interior, de puño de M. Franco presidente de Unión Nacionalista de la Patagonia ${ }^{54}$ donde se lo acusaba de propagar ideas extremistas a partir de sus vínculos con notables de la villa y por la posesión del cine local desde donde se difundían las ideas y propaganda. A partir de la investigación a cargo de asesoría letrada, en 1944, el Ministerio de Agricultura dejaba cesante a Gutiérrez.

Claro que el exfuncionario iría más allá cuando descubrió que, uno de los cargos en que se fundaba el decreto de cesantía, habría sido el vector comunista. Ya en 1945, en su carta dirigida al Ministro de Agricultura Amaro Avalos, solicitaba la reapertura del sumario y la rectificación como "salvaguardia de su patrimonio moral". Lo interesante del caso es que los conceptos emanados por Gutiérrez restituyen la capacidad con que se asignaba la acusación de comunista.

Por supuesto, Gutiérrez se manifestaba en dicha carta contrario al "sistema comunista" declarando sus intereses democráticos. En sus alegatos reponía que:

la imputación de comunismo, no es muchas veces, (mi caso es uno de ellos) sino un procedimiento para colocar a alguien fuera
de la ley. El objeto no es reprimir o investigar una conducta política que no posee ni práctica, sino aplicar sanciones arbitrarias
y privarle de sus derechos más elementales (...). El fuera de la ley, dúctil instrumento de venganza política es todavía hoy (...)
un procedimiento de venganza personal o política en manos de funcionarios inescropulosos. La imputación de comunismo
es una envoltura externa. 55

Semejante declaración se fundaba en el perjuicio lejano y arraigado del comisario Cuestas quien, según Gutiérrez, había organizado el sumario. Era el prototipo de la policía "brava moderna". Bravo porque se sentía "señor de vidas y haciendas" y moderno porque "a diferencia de sus antecesores de otras épocas (...) procede por caminos indirectos e inteligentemente y si alguien no se somete a sus deseos, lo detiene como presunto comunista" privándole de la libertad por seis meses o un año, en el marco de la aplicación de leyes represivas. ${ }^{56}$

Para concluir en la descripción del caso, se entablaba una relación directa entre el pedido y obtención del traslado del comisario de Villa Regina en su calidad de presidente de la comisión de fomento; invocando entre otras razones sumarios que el comisario tenía en su historial. En el esclarecimiento de los hechos, Gutiérrez, exponía el entramado del que se había servido el funcionario policial para propinar una campaña destinada a presentarlo como elemento comunista (valiéndose de los nacionalistas y deteniendo previamente a personas del establecimiento de su padre y algunos amigos). ${ }^{57}$

De la nueva investigación practicada en el transcurso de 1945, se obtuvo como prueba que Gutiérrez no había ejercido actividades políticas comunistas como tampoco se abocó a la selección de películas proyectadas en el cine Regina del que era copropietario. Pero la reciente pesquisa dejaba en evidencia dos cuestiones. En primer lugar, la existencia y el accionar de una entidad fascista conformada por extranjeros que profesaban su ideología y que atacaban a los que no se afiliaban o simpatizaban con ella; en un contexto donde los ánimos se agitaban por el estado de guerra. De modo que, los cargos iniciales formulados por Franco y las declaraciones obtenidas en el primer sumario pertenecían a todos correligionarios de esa agrupación; que concebían como "enemigos de Italia" o comunistas a aquellos que no pertenecían a la Fascio. En segundo lugar, estas actuaciones guardaban estrecha relación con las supuestas actividades comunistas en la localidad (mencionadas en el apartado anterior), que habían dado origen a la detención y puesta en libertad de varias personas por la policía territoriana en 1944. En aquel momento, el Ministerio del Interior había efectuado un dictamen por las irregularidades y deficiencias en el sumario realizado por el personal de la sección Orden Social. Este expediente y el cursado a Gutiérrez, confirmaban procedimientos de la policía "cuya información parecería encaminada a desfigurar la verdadera situación local". ${ }^{58}$ 


\section{CoNCLUSIÓN}

El recorrido en conjunto sobre las experiencias rionegrina y bonaerense ha permitido constatar la centralidad que para los cuerpos policiales de ambos espacios adquirieron las prácticas de seguimiento y represión, en el marco de la Argentina autoritaria que se inauguraría con el derrocamiento del gobierno nacional en 1930. Sobre una pléyade de intervenciones parcializadas, y en muchos casos inconexas, que al menos desde sus etapas formativas estas policías habían ensayado para el control de diversos actores sociales y políticos, el nuevo escenario habilitó un proceso de reforma y reorganización que conduciría a la especialización de las esferas burocráticas abocadas a la vigilancia. De modo tal, que sobre la referencia de la porteña Sección Especial se reestructuraron para comienzos de dicha década las Divisiones de Investigación y sus gabinetes respectivos.

Por un lado, la complejización del organigrama institucional respondía al desafío impuesto ante lo que agentes policiales y gubernamentales comenzarían a identificar como el peligro "comunista" creciente. Aunque la crisis no tuvo efectos directos que conllevaran a la radicalización del movimiento obrero organizado, desde una perspectiva amenazante para quienes estaban encargados de preservar el orden, fue la estrategia de expansión revolucionaria que -al menos como posibilidad- sostuvo la III Internacional la que concitó el despliegue del control y la represión policial. Ello supuso, asimismo, que la categorización de comunista tuviese usos más extendidos, siendo factible de aplicarse a una multiplicidad de actores a los que se catalogaría como "enemigos" del régimen: desde anarquistas, socialistas hasta radicales disidentes.

Claro que la precisión sobre el comunismo, en esta clave, se haría mucho más evidente desde mediados de los treinta. Lo que permite advertir acerca de las inflexiones producidas al interior de la década. La proximidad de la guerra y la posible situación de conflicto en su traspolación regional impulsó a un proceso de modernización, que se tradujo en la necesidad de revitalizar los convenios interpoliciales en una escala supranacional. Si bien la puesta en marcha de la Comisión de Actividades Antiargentinas y sus proyección al convenio de colaboración latinoamericana hicieron foco, desde lo dirigencial, en la producción e intercambio de información sobre actividades sospechosas con epicentro en la filtración comunista, aunque excediéndose para detectar también la diseminación del nazi-fascismo, el propósito de tales proyectos debe comprenderse como parte de un proyecto más amplio de profesionalización institucional. Cimentado sí en el perfeccionamiento como en el "préstamo" de diversas técnicas de vigilancia direccionadas sobre enemigos locales y externos, pero fundamentalmente en la búsqueda de articular a distintas esferas depositarias de funciones de seguridad, como las fuerzas armadas y la flamante gendarmería fundamentalmente. En este sentido, los años precedentes a la consolidación del peronismo, constituyeron un laboratorio significativo en la especialización de las experiencias policiales analizadas, que se integraron a una trama de modernización de sus funciones y reparticiones, perfeccionándose sobre todo en las estrategias de observación y persecución de múltiples actores englobados en el comunismo bajo la tormenta del mundo.

\section{REFERENCIAS}

Albornoz, M. y Galeano, D. (2017). Anarquistas y policías en el atlántico sudamericano: una red transnacional,1890-1910. Boletín del Instituto de Historia Argentina y Americana "Dr. Emilio Ravignani", (47), 101-134.

Águila, G. (2013). Las tramas represivas: continuidades y discontinuidades en un estudio de caso. La Dirección General de Informaciones de la Provincia de Santa Fe, 1966-1991. Sociobistórica, (31), 1-26. Recuperado de: https://ww w.sociohistorica.fahce.unlp.edu.ar/article/view/SHn31a01/pdf.

Águila, G. (2018). Policías, represión y "lucha antisubversiva”: exploraciones sobre el rol de las policías en el accionar represivo de los años 70 en Argentina. Folia Histórica del Nordeste, (32), 121-146. Recuperado de: https://revi stas.unne.edu.ar/index.php/fhn/article/view/3500/3137 
Ascolani, A. (2013). Trabajadores y sindicalismo. En J.M. Palacio, J.M. (dir.). Historia de la Provincia de Buenos Aires. De la federalización de Buenos Aires al advenimiento del peronismo (1880-1943), t. 4 (pp. 393-418). Buenos Aires: UNIPE / Edhasa.

Ballent, A. y Gorelik, A. (2001). País urbano o país rural: la modernización territorial y su crisis. En Cattaruzza, A. (ed.), Nueva Historia Argentinat. VII (pp. 143-200). Buenos Aires: Sudamericana.

Barreneche, O. (2019). De brava a dura. Policia de la provincia de Buenos Aires. Una historia (1930-1973). Rosario: Prohistoria.

Barry, V. (2019). Usos policiales para la represión política en las primeras décadas del siglo XX. En M. Franco, La violencia estatal en la Argentina del siglo XX. Programa Interuniversitario de Historia Política, Foro 7: La violencia estatal en la Argentina del siglo XX. Recuperado de: http://www. historiapolitica.com/datos/foros/ foro7_barryl.pdf

Bartolucci, M. (2020). Servicios de información, represión política, y violencia paraestatal durante el primer peronismo. Estudios sociales del Estado, 6(12), 87-118. Recuperado de: https://doi.org/10.35305/ese.v6i12.232

Baily, S. (1985). Movimiento obrero, nacionalismo y política en la Argentina. Buenos Aires: Hyspamérica Ediciones.

Béjar, M. D. (2005). El régimen fraudulento. La politica en la provincia de Buenos Aires, 1930-1943. Buenos Aires: Siglo XXI Editores.

Benclowicz, J. (2019). Un Estado dentro del Estado que ha creado un nuevo Código Penal: La Sección Especial de la Policía y la criminalización del comunismo hacia la década de 1930 en Argentina. Latin American Research Review, 54 (3), 623-636. Recuperado de: https://doi.org/10.25222/larr.165.

Berardi, P. (2019). "Crear la Policía" y construir el territorio. Las reformas policiales en un nuevo orden provincial: Buenos Aires, 1878-1880. Revista de Historia del Derecho, (58), 1-30. Recuperado de: http://www.scielo.org.ar /scielo.php?script $=$ sci_serial\&pid=18531784\&lng=es\&nrm=iso.

Bisso, A. (2005). Acción Argentina: un antifascismo nacional en tiempos de guerra mundial. Buenos Aires: Prometeo Libros.

Bisso, A. (2009). Sociabilidad, politica y movilización. Cuatro recorridos bonaerenses (1932-1943). Buenos Aires: Buenos Aires Libros.

Bohoslavsky, E. (2009). El Complotpatagónico. Nación, conspiracionismo y violencia en el sur de Argentina y Chile (siglos $X I X y X X)$. Buenos Aires: Prometeo.

Bohoslavsky, E. y Franco, M. (2020). Elementos para una historia de las violencias estatales en la Argentina del siglo XX. Boletin del Instituto de Historia Argentina y Americana Dr. Emilio Ravignani, 53, 119-123. Recuperado de: http://ppct.caicyt.gov.ar/index.php/ravignani/article/view/18351/pdf.

Caimari, L. (2012). Mientras la ciudad duerme. Pistoleros, policias y periodistas en Buenos Aires, 1920-1945. Buenos Aires: Siglo XXI Editores.

Carrizo, G. (2009). La Patagonia argentina en el período de entreguerras. Acerca de los orígenes de la Zona Militar de Comodoro Rivadavia. Antiteses, 2, 669-691.

Carrizo, G. (2018). Los trabajadores bajo el control policial en la Gobernación Militar de Comodoro Rivadavia, 1944-1955. En M. Moroni; F. Casullo y G. Carrizo, G. (comps) Justicia, seguridad y castigo. Concepciones y prácticas cotidianas en Patagonia, 1884-1955 (pp. 169-189). Rosario: Prohistoria.

Fernández Marrón, M. (2017). Que la policía haga policía. La formación policial en el Territorio Nacional de Río Negro (siglo XX). Cuadernos de Marte, 8(13), 117-148. Recuperado de: https://publicaciones.sociales.uba.ar/index.p $\mathrm{hp} /$ cuadernosdemarte/article/view/2675

Flier, P. (2015). Historia Reciente y desafíos de las fuentes: el Archivo de la Dirección de Inteligencia de la Policía de la Provincia de Buenos Aires. Travesía, 17(2), 81-88. Recuperado de: http://www.travesia-unt.org.ar/pdf//vol umen 172//04-Nota.pdf.

Franco, M. (2013). La seguridad interna como política de Estado en la Argentina del siglo XX. En R. Patto Sá Motta y Luciano Abreu (ed.), Autoritarismo e cultura politica, (33-64) Porto Alegre: Fundacao Gétulio Vargas e EDIPUCRS. 
Franco, M. (2020). Preguntas para pensar una pregunta: La violencia represiva en la Argentina del siglo XX. Programa Interuniversitario de Historia Politica, Foros de Historia Política. Buenos Aires. Recuperado de: http://historia politica.com/datos/biblioteca/represionestatal_franco.pdf.

Funes, P. (2004). Medio siglo de represión. El Archivo de la Dirección de Inteligencia de la Policía de la Provincia de Buenos Aires. Puentes, 4 (11), 35-43.

Galeano, D. (2018). Delincuentes viajeros. Estafadores, punguistasy policias en el Atlántico Sudamericano. Buenos Aires: Siglo XXI Editores.

Galeano, D. y Albornoz, M. (2020). A History of the City of Buenos Aires Police Bureau of Investigations, 18801910. En A. Carrizo de Reimann (comp.), Making Modern Police in Latin America: Beiträge zur Geschichte der Polizeien im 19. und 20. Jahrbundert, (pp. 37-64). Barleben: Leipziger Universitätsverlag GmbH.

García Ferrari, M. (2015). Marcas de identidad. Juan Vucetich y el surgimiento transnacional de la dactiloscopia, 1883-1913. Rosario: Prohistoria.

Gorelik, A. (2015). Terra incógnita. Para una comprensión del Gran Buenos Aires como Gran Buenos Aires. En G. Kessler (dir.). Historia de la Provincia de Buenos Aires: el Gran Buenos Aires, t. 6 (pp. 21-69). Buenos Aires: UNIPE / Edhasa.

Jordán, C. (1988). Los presos de Bragado. Buenos Aires: Centro Editorial de América Latina.

Kalmanowiecki, L. (1997). Military Power and Policing in Argentina 1900-1955 (Tesis doctoral). Nueva York: New School for Social Research.

Lida, M. (2009). Los orígenes del catolicismo de masas en la Argentina, 1900-1934. Jabrbuch für Geschichte Lateinamerikas, (46), 345-370. Recuperado de: http://historiapolitica.com/datos/biblioteca/catolicismo\%20e spyarg_lida.pdf.

López, N. (2021). Tras los pasos del anarquismo y el radicalismo. El accionar de la División de Investigaciones de Rosario (1906-1912). Coordenadas, 8(1), 23-40.

López Cantera, M. (2014). Criminalizar al rojo. La represión al movimiento obrero en los informes de 1934 sobre la Sección Especial. Archivos de historia del movimiento obrero y la izquierda, (4),101-122. Recuperado de: https:/ /www.archivosrevista.com.ar/numeros/index.php/archivos/article/view/106.

Luciano, M. (2019). Innovaciones jurídicas, oportunidades políticas y cambios en la Policía de la Capital: el proceso de reforma del Código Procesal Penal en Córdoba (Argentina) en la década de 1930. Revista Historia y Justicia, 12, 1-27. Recuperado de: https://doi.org/10.4000/rhj.1749

Luciano, M. (2021). Despliegue técnico, expansión burocrática y conflictos políticos: el accionar policial en tiempos del Sabattinismo (1936-1943), Córdoba-Argentina. Historelo. Revista de Historia Regional y Local, 13 (26), 187-222. Recuperado de: https://doi.org/10.15446/historelo.v13n26.85433.

Marengo, M. E. (2012). Lo aparente como real. Un análisis del sujeto comunista en la creación y consolidación del servicio de inteligencia de la policía de la provincia de Buenos Aires (1930-1962). Los Polvorines: Universidad Nacional de General Sarmiento.

Muñiz, Fors y Gambier (1911). La policia de la provincia de Buenos Aires. Su Historia, su Organización, sus Servicios. La Plata: Taller de Impresiones Oficiales.

Nazar, M. (2018). Secretos, reservados y confidenciales: la producción de las fuerzas armadas y de seguridad como fuente para la historiografía. Estudios Sociales del Estado, 4 (7), 243-264. Recuperado de: http://www.estudioss ocialesdelestado.org/index.php/ese/article/view/151/117.

Nieto, A. (2018). Entre anarquistas y peronistas. Historias obreras a ras del suelo. Buenos Aires: Ediciones CEHTI / Imago Mundi.

Scocco, M. (2019). Las fuerzas represivas y las divisiones de inteligencia. El Ejército y las policías en Rosario (1966-1979). Revista de Estudios sobre Genocidio, 14, 11-28. Recuperado de: http://revistas.untref.edu.ar/inde x.php/reg/issue/view/27/REG\%2014\%20completa.

Suárez, G. (2013a). La sección 'Orden Social' de la policía de Río Negro (Argentina). Qué se vigila, cómo se registra, a quiénes se reprime (1931-1944).E.I.A.L., 24(2), 63-64. 
Suárez, G. (2013b). La represión política en Río Negro en las décadas de 1930 y 1940. El caso de los anarquistas. Archivos de historia del movimiento obrero y la izquierda (3), 107-129.

Suárez, G. (2020). Nacionalistas y aliadófilos en clave local: Villa Regina, Río Negro durante la década de 1940. Coordenadas, 7(1), 1-17

Rafart, G. y Mases, E. (2003). Economía, sociedad y política en los tiempos preperonistas. En G. Rafart y E. Mases (dirs.). El peronismo desde los territorios a la Nación: su historia en Neuquén y Rio Negro, 1943-1958 (pp.17-44). Neuquén: Universidad Nacional de Comahue.

Ruffini, M. (2011). Hay que argentinizar la Patagonia. Miradas sobre la Nación y la ciudadanía en tiempos de cambio (1916-1930). Anuario de Estudios Americanos 68 (2), 649-672.

V.V.A.A. (1981). Sintesis histórica de la Policía de la Provincia de Buenos Aires 1580-1980. La Plata: Policía de la Provincia de Buenos Aires.

\section{Notas}

1 A partir de 1955, Río Negro dejaría atrás su condición territoriana para "convertirse" en provincia. Sin embargo, el golpe de Estado de ese año y su intervención en las autonomías provinciales retrasó su efectivo gobierno electivo hasta 1958.

2 La policía territoriana quedó formalmente creada en 1884, bajo la sanción de la ley $\mathrm{N}^{\circ} 1532$. Sin embargo, recién en 1887 se le asignó parte del presupuesto nacional.

3 Archivo Histórico Provincial de Río Negro (AHPRN), Orden del Día N 2491, 10 de febrero de 1945. Revista Administrativa, No 81, marzo de 1945, p. 41. Archivo General de la Nación - Departamento de Archivo Intermedio (AGN-DAI), Fondo Ministerio del Interior (FMdI), Sección Dirección de Territorios Nacionales, Serie Personal, Legajo N³57, Expediente $N^{\circ} 1579 \mathrm{~J} / 47$.

4 AGN-DAI, FMdI, Expedientes secretos, confidenciales y reservados, N442, 30.194/G-944, 7 de julio de 1944 , caja 18.

5 Desde su conformación, hacia fines de 1880, la fuerza policial de la provincia estuvo permeada por sucesivas instancias de reforma. Para más detalles, véase Berardi (2019).

6 De acuerdo con las narrativas construidas por las distintas fracciones del conservadurismo dicha definición fue empleada, hasta 1943, para referir incluso de manera conmemorativa, al golpe de Estado llevado a cabo el 6 de septiembre de 1930. Con el que se puso fin al predominio del radicalismo de extracción yrigoyenista.

7 La División de Investigaciones fue presidida por la Comisaría de Pesquisa que, también inspirada en su par porteña, comenzó a funcionar en 1890 en las instalaciones de la Comisaría Tercera de La Plata. Sus alcances no obstante fueron acotados y la intervención de su personal se circunscribió, excepto en algunas ocasiones, al radio de la capital bonaerense. En los umbrales del novecientos, además de transformarse en Comisaría de Investigaciones se ramificó al dividirse en dos secciones, cuya estructura se mantuvo inalterable poco más del centenario: una concentrada en "robos y hurtos, defraudaciones y estafas, impresiones dactiloscópicas, orden social y fotografía” y otra que atendía la "seguridad personal, informaciones y leyes especiales, libros y vigilancia general” (Muñiz, Fors y Gambier, 1911, p. 79-81). Sería reorganizada entonces a comienzos del nuevo siglo, con la ampliación de dos sub-comisarías localizadas en las ciudades de Bahía Blanca y Avellaneda, entre 1907 y 1909. Hacia 1912 empero, la Jefatura avanzó sobre su reestructuración estableciendo a sus ramas internas en los siguientes gabinetes: de Seguridad Personal, de Robos y Hurtos, de Defraudaciones y estafas, de libros e informaciones y Gabinete de Orden social y leyes especiales, al que se le añadió una "Sección Política".

8 Provincia de Buenos Aires, Memoria del Ministerio de Gobierno, Tomo I, 18/2/1936-30/4/1937, Taller de Impresiones Oficiales, La Plata, 1937, p. 125.

9 Revista de Policía de la Provincia de Buenos Aires, Año II, No 19, noviembre de 1942, 145.

10 Desde los años veinte, las policías sudamericanas mantenían una fluida comunicación ratificada en Convenios y Conferencias (Galeano, 2018).

11 Para más detalles sobre la creación de la Comisión Argentina de Actividades Antiargentinas, véase Luciano (2021) y Bisso (2005).

12 AGN-DAI, FMdI, Expedientes secretos, confidenciales y reservados, №273, Letra P, 1941, caja 4.

13 AGN-DAI, FMdI, Expedientes secretos, confidenciales y reservados, №273, Letra P, 1941, caja 4.

14 Se reiteraba la necesidad de crear una sección especial en las policías provinciales y territorianas. Tendrían por finalidad practicar: a) el intercambio de información; b) comunicarse entre sí y con la Nación sobre denuncias, vigilancias, comprobaciones y procedimientos policiales y judiciales sobre individuos u organismos sospechosos y, el tránsito interjurisdiccional de personas; c) promover la vigilancia y sanciones que correspondan sobre escuelas o institutos que realizaren enseñanzas de "exclusión argentinista o contraria a la orientación patriótica, democrática y americanista"; d) 
intervenir en los casos de extradición interprovincial por los delitos enunciados en los puntos anteriores. AHCDNA, Fondo Comisión Especial Investigadora de Actividades Antiargentinas (FCEIAA), PE, Expediente N 93, folio 4.

15 AHCDNA, FCEIAA, PE, Expediente $N^{\circ}$ 93, folio 6-7.

16 AHCDNA, FCEIAA, PE, Expediente $N^{\circ} 141,28$ de septiembre de 1942.

17 Acta Final de la Tercera Reunión de Consulta de Ministros de Relaciones Exteriores de las Repúblicas Americanas, Río de Janeiro, 15 al 28 de enero de 1942, capítulo XVIII, pág. 123-124. Recuperado de: https://www.oas.org/consejo/sp/ rc/Actas/Acta\%203.pdf. El destacado en cursivas ha sido realizado por les autores.

18 Acta Final de la Tercera Reunión de Consulta de Ministros de Relaciones Exteriores de las Repúblicas Americanas, Río de Janeiro, 15 al 28 de enero de 1942, capítulo XVIII, pág. 125. Recuperado de: https://www.oas.org/consejo/sp/rc/ Actas/Acta\%203.pdf.

19 Acta Final de la Tercera Reunión de Consulta de Ministros de Relaciones Exteriores de Repúblicas Americanas, Río de Janeiro, 15 al 28 de enero de 1942, capítulo XVIII, pág. 125-126. Recuperado de: https://www.oas.org/consejo/sp/rc /Actas/Acta\%203.pdf.

20 Dentro de la delegación argentina se presentaron seis proyectos. Del listado de proyectos se traduce que, además de una legislación específica de emergencia, se deseaba promover una normativa jurídico-penal. Aún más, revelaba la intención de crear la "Unión Interamericana de Policía”. AHCDNA, FCEIAA, Expediente Nº141, 28 de septiembre de 1942.

21 BN, Hem, Lucas Jordan Rebecchi, "La Gendarmería Nacional”, Revista de Policía y Criminalistica de Buenos Aires, N ${ }^{\circ} 8,1936$.

22 AGN-DAI, FMdI, Expedientes secretos, confidenciales y reservados, N79, caja 4.

23 AGN-DAI, FMdI, Expedientes secretos, confidenciales y reservados, N609, 4 agosto de 1944, caja 20. Como ejemplo, en 1944, se creó la Gobernación Militar de Comodoro Rivadavia, una jurisdicción política-administrativa que modificó los límites de territorios nacionales de Chubut y Santa Cruz (Carrizo, 2009, 2018).

24 Acción Argentina fue una heterogénea agrupación de cuño liberal-socialista, que se dio en torno de una prédica antifascista abocada no solo a la lucha contra la penetración nazi, sino también en la defensa nacional. Surgida hacia fines de la década de 1930 fue disuelta en el marco de la derrotada Unión Democrática en 1946. Para más detalles, véase Bisso (2005).

25 AGN-DAI, FMdI, Expedientes secretos, confidenciales y reservados, № 162, 1943, caja 8.

26 Ibid.

27 Entre los conferencistas se hallaba Alicia Moreau de Justo, el diputado nacional Demetrio Buira, la profesora M. B. y el señor E. R.

28 El 17 de febrero de 1943, el Jefe del Escuadrón de Gendarmería Nacional elevaba una nota al Jefe de la Agrupación Militar Bariloche (Napoleón Irusta) con el objetivo de "producir informe" sobre lo acontecido en el acto de Acción Argentina. AGN-DAI, FMdI, Expedientes secretos, confidenciales y reservados, $N^{\circ} 162$, 1943, Gobernación de Río Negro, caja 8.

29 Boletín informativo $\mathrm{N}^{\circ} 1$ correspondiente al mes de enero de carácter político, Ejército Argentino, Agrupación Bariloche, Teniente Comandante Napoleón Irusta, 23 de enero de 1943. AGN-DAI, FMdI, Expedientes secretos, confidenciales y reservados, $\mathrm{N}^{\circ} 162,1943$, caja 8.

30 Dictamen de la Auditoría General de Guerra y Marina N 115134, 23 de marzo de 1943. AGN-DAI, FMdI, Expedientes secretos, confidenciales y reservados, $\mathrm{N}^{\circ} 162$, caja 8.

31 AGN-DAI, FMdI, Expedientes secretos, confidenciales y reservados, N 162, 12 de abril de 1943, caja 8.

32 Revista Administrativa, N'81, marzo de 1945, p.37.

33 AGN-DAI, FMdI, Sección Dirección de Territorios Nacionales, Serie Personal, Legajo N³62; Expedientes secretos, confidenciales y reservados, $\mathrm{N}^{\circ} 203$, caja 16.

34 Sobre los movimientos nacionalistas/neutralistas y aliadófilos/demócratas, sus inicios y actividades en los años ‘ 40 , en Villa Regina (Suárez 2020)

35 AGN-DAI, FMdI, Expedientes secretos, confidenciales y reservados, N²03, Letra g, N700, 17 de Junio de 1945, caja 16.

36 AGN-DAI, FMdI, Expedientes secretos, confidenciales y reservados, № 203, 45.856-J-1944, caja 16.

37 AGN-DAI, FMdI, Sección Dirección de Territorios Nacionales, Serie Personal, Legajo N³62.

38 AGN-DAI, FMdI, Expedientes secretos, confidenciales y reservados, N²03, Letra g, N700, 17 de Junio de 1945, caja 16.

39 AHPLP, Orden del Día N³048, 29 de diciembre de 1942, libo 93.

40 Revista Administrativa, N81, marzo de 1945, p.23.

41 AGN-DAI, FMdI, Expedientes secretos, confidenciales y reservados, N¹32, 18 de mayo de 1942, caja 5.

42 Revista Administrativa, N'81, marzo de 1945, p. 23.

43 En la década de 1910, se habían conformado las Oficinas de Identificación Dactiloscópica que se generalizaron rápidamente en cada una de las comisarías de los territorios y en Provincia de Buenos Aires. 
44 Revista Administrativa, N'81, marzo de 1945, p. 23.

45 AHPLP, Orden del Día N³248, 12 de enero de 1945, libro 105; Revista Administrativa, N81, marzo de 1945 , p. 23.

46 Provincia de Buenos Aires, Memoria presentada a la Honorable Legislatura por el Ministro de Gobierno, Dr. Marco Aurelio Avellaneda, Tomo I: Política, 1932-1933, La Plata, Taller de Impresiones oficiales, 1933, pp. 133-149.

47 Diario de Sesiones, Senado de la Provincia de Buenos Aires, 1934, Tomo I, La Plata, Taller de Impresiones oficiales, 1936. 26/6/1934, 6ta sesión ordinaria, p. 281.

48 En cursivas en el original.

49 Ibíd., 282.

50 Ibíd., 7 ma reunión ordinaria, 3/7/1934, p. 354. El subrayado es nuestro.

51 Ibíd., p. 340.

52 Ibíd., p. 339.

53 El estado bonaerense, durante la gestión fresquista, consumaría tal identificación en una persecución exacerbada sostenida a partir de la sanción de un decreto para la represión del Comunismo en mayo de 1936.

54 La Unión Nacionalista de la Patagonia tenía un pasado ligado al fascismo. La sociedad Dopolavoro Litoria -Cezione Fascista tuvo que disolverse en 1939 por disposición del Poder Ejecutivo Nacional; formándose posteriormente la Unión nacionalista de la Patagonia a la que ingresaron los miembros de la anterior entidad. AGN-DAI, FMdI, Expedientes secretos, confidenciales y reservados, N $^{\circ} 903$, Legajo 69/943, abril de 1945, caja 23.

55 Ibíd.

56 Ibíd.

57 Gutiérrez hace referencia a la detención expuesta previamente por Agustín Galissier y otros policías.

58 AGN-DAI, FMdI, Expedientes secretos, confidenciales y reservados, Nº03, Memorandum 903/944, 18 de julio de 1946 , caja 23. 